\title{
Salt, Glucose, and Hypertension: Interactions, Benefits and Risk
}

\author{
Seriki A Samuel* \\ Department of Human Physiology, College of Medicine, Bingham University, Nigeria
}

Submission: February 10, 2017; Published: April 03, 2017

*Corresponding author: Seriki A Samuel, Department of Human Physiology, College of Medicine, Bingham University, Karu, Nigeria, Tel: +2348036041121; Email: seriki.adinoyi@gmail.com

\begin{abstract}
Both dietary salt and sugar are related to blood pressure (BP) and hypertension. The evidence for salt was initially considered stronger, and various types of studies have consistently shown that salt is a major cause of raised BP, and a reduction from the current intake of between $9-12 \mathrm{~g} /$ day in most countries of the world to a recommended level of no more than 6 gram (i.e. 2.5 grams of sodium) on a daily basis (an approximate of 1 teaspoon of salt per day) will lower BP in both hypertensive and normotensive individuals, in men and women of all age groups and in all the black and the Caucasians. The physiology by which salt raises causes hypertension has to do with the kidney using a delicate balance of sodium and potassium to pull water across a wall of cells from the bloodstream into a collecting channel that leads to the bladder. A high salt intake raises the amount of sodium in the bloodstream and distorts this delicate balance, thereby reducing the ability of the kidneys to remove the water. This causes fluid retention which increases the pressure exerted by the blood against blood vessel walls (high blood pressure). The sugar also is a factor that increases BP. It is in fact, recently considered that sugar may have more devastating effect of BP than salt. The mechanism by which sugar interacts with BP has to do with insulin and leptin levels in the body. It causes blood pressure to increase, and eventually, there may become insulin and/or leptin resistant. Insulin stores magnesium, but if its receptors are blunted and the cells grow resistant to insulin, the body can't store magnesium, so it passes out of the body through urination. Magnesium stored in the cells relaxes muscles. If its level is too low, the smooth muscle of the blood vessels will be unable to fully relax, and this constriction raises blood pressure. The current high intake of added sugars increases obesity which, in turn, raises BP. Recent studies also suggest that added sugars, particularly those in soft drinks, may have a direct effect on BP. Actions to reduce salt and sugar intake across the world population have been recommended in this review, and will go a long way to having beneficial effects on health along with major cost savings from treatments.
\end{abstract}

Keywords: Salt; Sugar; Hypertension; Sodium; Potassium; Insulin; Magnesium

\section{Introduction}

\section{Blood pressure}

Blood pressure is the force of blood against the walls of arteries. Blood pressure has two components: the systolic pressure (which is the force that blood exerts on the artery walls when the heart pumps), and the diastolic pressure (which is the residual force that remains when the heart relaxes between beats).

The measurement is written one above the other, with the systolic number on top and the diastolic number on the bottom. For example, a blood pressure measurement of $130 / 85 \mathrm{mmHg}$ (millimeters of mercury) is expressed verbally as «130 over $85 »$. The systolic is 130 and the diastolic is 85 .

Blood pressure varies from person to person and by age. In general: Normal blood pressure is less than $130 \mathrm{mmHg}$ systolic and less than $85 \mathrm{mmHg}$ diastolic. Optimal blood pressure is less than $120 \mathrm{mmHg}$ systolic and less than $80 \mathrm{mmHg}$ diastolic.

\section{Hypertension}

Table 1: Categories for Blood Pressure Levels in Adults* (Ages 18 Years and Older).

\begin{tabular}{|c|c|c|}
\hline \multicolumn{3}{|c|}{ Blood Pressure Level $(\mathbf{m m ~ H g})$} \\
\hline Category & Systolic & Diastolic \\
\hline Optimal $^{* *}$ & $<120$ & $<80$ \\
\hline Normal $^{\mid}$High Blood Pressure \\
\hline High Normal & $<130$ & $<85$ \\
\hline \multicolumn{3}{|c|}{$130-139-89$} \\
\hline Stage 1 & $140-159$ & $90-99$ \\
\hline Stage 2 & $160-179$ & $100-109$ \\
\hline Stage 3 & $\geq 180$ & $\geq 110$ \\
\hline
\end{tabular}


*For those not taking medicine for high blood pressure and not having a short-term serious illness. These categories are from the National High Blood Pressure Education Program

**Optimal blood pressure with respect to heart disease risk is below $120 / 80 \mathrm{~mm} \mathrm{Hg}$. However, unusually low readings should be evaluated for clinical significance.

$<$ : Less than

z: Greater than or equal to

Hypertension is generally defined as a blood pressure greater than 140/90mmHg. Blood pressure should be brought closer to what's considered optimal: 120/80. An elevated blood pressure raises the risk for heart attack and stroke. Depending on other risk factors, even the high end of normal may be too high for some people (Table 1).

\section{Types of hypertension}

There are two primary hypertension types. For 95 percent of people with high blood pressure, the cause of their hypertension is unknown; this is called Essential or Primary hypertension. When a cause can be found, the condition is called Secondary hypertension.

Essential hypertension: This type of hypertension is diagnosed after blood pressure remains high after about three or more measurements and all other causes of hypertension are eliminated. Usually people with essential hypertension have no symptoms, but may experience frequent headaches, tiredness, dizziness, or nose bleeds. Although the cause is unknown, researchers have observed that obesity, smoking, alcohol, diet, and heredity all play a role in essential hypertension.

Secondary hypertension: The most common cause of secondary hypertension is an abnormality in the arteries supplying blood to the kidneys. Other causes include airway obstruction during sleep, diseases and tumors of the adrenal glands, hormone abnormalities, thyroid disease, and too much salt or alcohol in the diet. Drugs can cause secondary hypertension, including over-the-counter medications such as ibuprofen (Motrin, Advil, and others) and pseudoephedrine (Afrin, Sudafed, and others). If the cause is found, hypertension can often be controlled.

Additional hypertension types: isolated systolic, malignant, and resistant

Isolated systolic hypertension, malignant hypertension, and resistant hypertension are all recognized hypertension types with specific diagnostic criteria.

Isolated systolic hypertension: Blood pressure is recorded in two numbers: The upper, or first, number is the systolic pressure, which is the pressure exerted during the heartbeat; the lower, or second, number is the diastolic pressure, which is the pressure as the heart is resting between beats. Normal blood pressure is considered under 120/80. With isolated systolic hypertension, the systolic pressure rises above 140, while the lower number stays near the normal range, below 90 . This type of hypertension is most common in people over the age of 65 and is caused by the loss of elasticity in the arteries. The systolic pressure is much more important than the diastolic pressure when it comes to the risk of cardiovascular disease for an older person.

Malignant hypertension: This hypertension type occurs in only about 1 percent of people with hypertension. It is more common in younger adults, African-American men, and women who have pregnancy toxemia. Malignant hypertension occurs when the blood pressure rises extremely quickly, with the diastolic pressure going over 130 . Symptoms include numbness in the arms and legs, blurred vision, confusion, chest pain, and headache.

Resistant hypertension: This is when a high blood pressure remains high even after three different types of antihypertensive medications are administered to a patient. Resistant hypertension may occur in 20 to 30 percent of high blood pressure cases. It may have a genetic component and is more common in people that are older, obese, female, AfricanAmerican, or have an underlying illness, such as diabetes or kidney disease.

\section{Salts and sugar}

Salts: Salts are compounds made up of cations (e.g., $\mathrm{K}+, \mathrm{Ca}^{2+}$, $\left.\mathrm{NH}^{4+}\right)$ and anions, such as chloride $\left(\mathrm{Cl}^{-}\right)$, nitrate $\left(\mathrm{NO}_{3}{ }^{-}\right.$, that are held together by ionic bonds. They are crystalline materials.

Salts normally consist of positively charged ions, cations, and negatively charged ions, anions, that form a crystal lattice. In addition, some salts may include the water molecule $\left(\mathrm{H}_{2} \mathrm{O}\right)$ in the lattice; they are referred to as hydrated salts (Figure 1).

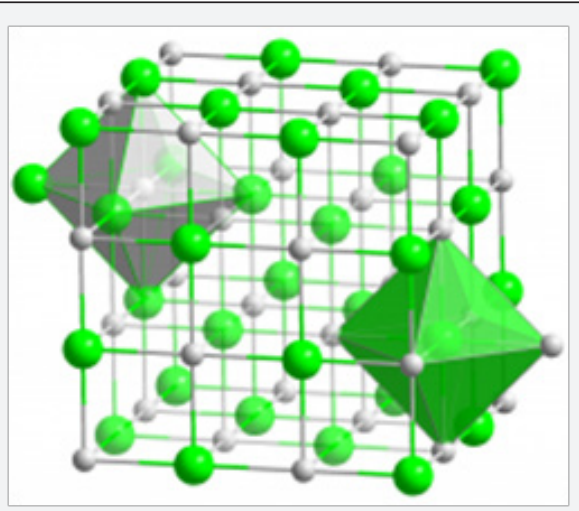

Figure 1: The crystal lattice of $\mathrm{NaCl}$.

Salts, by definition, are the result of a neutralization reaction, i.e., the mixture of an acid with a base.

Base + Acid $\rightarrow$ Salt + Water

\section{Characteristics and classification of salts}

While some salts, such as $\mathrm{NaCl}$ are neutral, that is, their solution does not change the normal pH 7 of water, other salts 
may be alkaline or acidic, depending on the strength of the participating acids and bases:

1. Strong acid + strong base $\rightarrow$ neutral salt + water

2. Strong acid + weak base $\rightarrow$ acidic salt + water

3. Weak acid + strong base $\rightarrow$ alkaline salt + water

Examples:

1. $\mathrm{H}_{3} \mathrm{O}^{+}+\mathrm{Cl}^{-}+\mathrm{Na}^{+}+\mathrm{OH}^{-} \rightarrow \mathrm{NaCl}+\mathrm{H}_{2} \mathrm{O}$

2. $\mathrm{H}_{3} \mathrm{O}^{+}+\mathrm{Cl}^{-}+\mathrm{NH}_{3} \rightarrow \mathrm{NH}_{4} \mathrm{Cl}+\mathrm{H}_{2} \mathrm{O}$

3. $\mathrm{H}_{3} \mathrm{O}^{+} \mathrm{HCO}_{3}^{-}+2 \mathrm{Na}^{+}+2 \mathrm{OH}^{-} \rightarrow \mathrm{Na}_{2} \mathrm{CO}_{3}+3 \mathrm{H}_{2} \mathrm{O}$

Salts may have different solubilities; while some salts are very soluble, others may be practically insoluble. In general, soluble salts are more «damaging» to inorganic porous materials than the less soluble ones.

The formula for sodium chloride, $\mathrm{NaCl}$, indicates that equal numbers of sodium and chlorine atoms combine to form the salt. Ionically, in the reaction of sodium with chlorine, each sodium atom loses an electron, becoming positively charged, and each chlorine atom gains an electron, becoming negatively charged; there are equal numbers of positively charged sodium ions and negatively charged chloride ions in sodium chloride. The ions in a solid salt are usually arranged in a definite crystalline structure, each positive ion being associated with a fixed number of negative ions, and vice versa.

A salt that has neither hydrogen $(\mathrm{H})$ nor hydroxyl $(\mathrm{OH})$ in its formula, e.g., sodium chloride ( $\mathrm{NaCl})$, is called a normal salt. A salt that has hydrogen in its formula, e.g., sodium bicarbonate $\left(\mathrm{NaHCO}_{3}\right)$, is called an acid salt. A salt that has hydroxyl in its formula, e.g., basic lead nitrate $\left(\mathrm{Pb}[\mathrm{OH}] \mathrm{NO}_{3}\right)$, is called a basic salt. Since a salt may react with a solvent to yield different ions than were present in the salt, a solution of a normal salt may be acidic or basic; e.g., trisodium phosphate, $\mathrm{Na}_{3} \mathrm{PO}_{4}$, dissolves in and reacts with water to form a basic solution.

In addition to being classified as normal, acid, or basic, salts are categorized as simple salts, double salts, or complex salts. Simple salts, e.g., sodium chloride, contain only one kind of positive ion (other than the hydrogen ion in acid salts). Double salts contain two different positive ions, e.g., the mineral dolomite, or calcium magnesium carbonate, $\mathrm{CaMg}\left(\mathrm{CO}_{3}\right)_{2}$. Alums are a special kind of double salt. Complex salts, e.g., potassium ferricyanide, $\mathrm{K}_{3} \mathrm{Fe}(\mathrm{CN})_{6}$, contain a complex ion that does not dissociate in solution. A hydrate is a salt that includes water in its solid crystalline form; Glauber's salt and Epsom salts are examples of hydrates.

Salts are often grouped according to the negative ion they contain, e.g., bicarbonate or carbonate, chlorate, chloride, cyanide, fulminate, nitrate, phosphate, silicate, sulfate, or sulfide.

\section{Sugar}

Sugar is the generalized name for sweet, short-chain, soluble carbohydrates, many of which are used in food. They are composed of carbon, hydrogen, and oxygen. There are various types of sugar derived from different sources. Simple sugars are called monosaccharides and include glucose (also known as dextrose), fructose, and galactose. The table or granulated sugar most customarily used as food is sucrose, a disaccharide. In the body, sucrose hydrolyses into fructose and glucose. Other disaccharides include maltose and lactose. Longer chains of sugars are called oligosaccharides. Chemically, different substances may also have a sweet taste, but are not classified as sugars. Some are used as lower-calorie food substitutes for sugar described as artificial sweeteners.

Studies in animals have suggested that chronic consumption of refined sugars can contribute to metabolic and cardiovascular dysfunction. Some experts have suggested that refined fructose is more damaging than refined glucose in terms of cardiovascular risk. Cardiac performance has been shown to be impaired by switching from a carbohydrate diet including fiber to a high-carbohydrate diet [1]. Switching from saturated fatty acids to carbohydrates with high glycemic index values shows a statistically-significant increase in the risk of myocardial infarction [2]. Other studies have shown that the risk of developing coronary heart disease is decreased by adopting a diet high in polyunsaturated fatty acids but low in sugar, whereas a low-fat, high-carbohydrate diet brings no reduction. This suggests that consuming a diet with a high glycemic load typical of the «junk food» diet is strongly associated with an increased risk of developing coronary heart disease [3].

The consumption of added sugars has been positively associated with multiple measures known to increase cardiovascular disease risk amongst adolescents as well as adults [4]. Studies are suggesting that the impact of refined carbohydrates or high glycemic load carbohydrates is more significant than the impact of saturated fatty acids on cardiovascular disease [5,6]. A high dietary intake of sugar (in this case, sucrose or disaccharide) can substantially increase the risk of heart and vascular diseases.

\section{Salt, Sugar and Hypertension}

\section{Salt and hypertension}

Interactions: It has been established in chapter one that blood pressure is the relationship between the amount of blood ejected from the heart with each heartbeat and the resistance against which it ejects, and that systolic blood pressure is the peak pressure generated by the volume of blood ejected and diastolic pressure the pressure in blood vessels during the period between heartbeats (the time the heart fills with blood between beats is called «diastole»). The cardiac output is determined by the amount of blood in the heart at 
the beginning of a beat and so is dependent on the total blood volume.

Arthur Guyton, a physiologist had postulated the theory of «pressure natriuresis». It basically states that every patient with high blood pressure has a disorder of salt handling by the kidney. The appropriate response to increased blood pressure is increased salt excretion through the kidney. A large body of experimental data does indeed point to abnormally slow salt excretion by the kidney as an important component of human hypertension [7].

Cogent evidences indicate that salt intake is strongly related to the development of hypertension, particularly the rise in blood pressure with age [7]. The risk of cardiovascular disease increases throughout the range of blood pressure starting from a systolic blood pressure of $115 \mathrm{mmHg}[8,9]$ which $80 \%$ of the adult population exceeds. Raised blood pressure is the major cause of the development of cardiovascular disease, and accounts for $60 \%$ of all strokes and $50 \%$ of all heart disease [10]. Blood pressure is the biggest cause of death in the world through the strokes and heart attacks it causes.

How salts specifically interact with blood pressure (Hypertension): The kidney uses a delicate balance of sodium and potassium to pull water across a wall of cells from the bloodstream into a collecting channel that leads to the bladder.

A high salt intake raises the amount of sodium in the bloodstream and wrecks the delicate balance, reducing the ability of the kidneys to remove the water. This causes fluid retention which increases the pressure exerted by the blood against blood vessel walls (high blood pressure).

\section{Risks}

On the arteries: The extra blood pressure caused by eating too much salt puts extra strain on the insides of the arteries. To cope with the extra strain, the tiny muscles in the artery walls become stronger and thicker. Yet this only makes the space inside the arteries smaller and raises the blood pressure even higher.

This cycle of increasing blood pressure (which occurs slowly over a number of years) can ultimately lead to the arteries bursting or becoming so narrow that they then clog up entirely. When this happens, the organs of the body that were receiving the blood from the arteries become starved of the oxygen and nutrients they need. This can result in the organs being damaged.

On the heart: The raised blood pressure caused by eating too much salt may damage the arteries leading to the heart. At first, it may cause a slight reduction in the amount of blood reaching the heart. This may lead to angina (sharp pains in the chest when being active).

With this condition, the cells in the heart don't work as well as they should because they are not receiving enough oxygen and nutrients. However, lowering blood pressure may help to alleviate some of the problems and reduce the risk of greater damage.

But if the salt intake is not controlled over time, the damage caused by the extra blood pressure may become so severe that the arteries burst or become completely clogged. If this happens, then the part of the heart that was receiving the blood no longer gets the oxygen and nutrients it needs and dies. The result is a heart attack. The best way to prevent a heart attack is to stop the arteries becoming damaged. And one of the best ways of doing this is keep the blood pressure down by eating less salt.

On the brain: The raised blood pressure caused by increased intake of salt may damage the arteries leading to the brain. At first, it may cause a slight reduction in the amount of blood reaching the brain. This may lead to vascular dementia.

With this condition, the cells in the brain don't work as well as they should because they do not receive enough oxygen and nutrients. However, lowering blood pressure may help to alleviate some of the problems and reduce the risk of greater damage.

With uncontrolled intake of salt over time, the damage caused by the extra blood pressure may become so severe that the arteries burst or become completely clogged. This leads to the death of part of the brain that was receiving the blood as result of no longer getting oxygen and nutrients it needs to function. The result is a stroke, where the body loses the ability to do the things that part of the brain used to control.

Benefits: Common salt, also known as sodium chloride, is a common ingredient used for seasoning purposes in our everyday foods. It is available in a range of diverse forms and particle sizes, depending on the proposed use.

The salt/water ratio is critical for the metabolic rate of our body. Salt facilitates sending signals in the nerves and muscles and helps sustain the fluid content inside and outside the blood cells. Dietary salt exists in various forms: unrefined, refined (also known as table salt) and iodine-fortified salt. It offers a variety of health benefits.

Blood pressure and cardiovascular health: It has been proven that dietary salt determines the blood pressure of the body and has an impact on cardiovascular health, which is primarily related to strokes and heart attacks. Inadequate intake of salts like calcium, magnesium, and sodium can cause health issues could result in hypotension.

So, Low Blood Pressure (hypotension) (reading below 90/60) can be treated by consuming more salt and hydrating fluids. This will help boost the volume of blood in the arteries, resulting in a rise in blood pressure to normal value.

Heat stroke or sun stroke: Heat Stroke is a condition that occurs when the body's heat regulating system falls short. This 
can occur both by being out in the hot sun for a long duration as well as overheating in the surrounding environment, such as work areas. The body fails to release heat properly in order to attain its normal temperature. As a result, the body temperature becomes too high, which poses a threat to the major organs. In an attempt to cool itself down, the body produces more sweat through the sweat glands, thereby losing essential salt (sodium) and water.

The elderly and small babies are at greater risk of heat stroke, since their body's thermostat lacks efficiency. Prevention of heat or sun stroke is always advisable by keeping the body hydrated and consuming adequate amounts of salt in order to maintain the electrolyte balance. A person suffering from heat stroke can be treated by offering water or fluids that contain sugar and salt.

Other health benefits of salts include: prevention of goiter or hyperthyroidism and mental retardation which result from deficiency of iodine; Oral Rehydration Treatment which is essential for sustaining the hydration levels of the body-these electrolytes primarily entail magnesium, potassium, calcium, and sodium. Also, in diabetes, healthy levels of insulin are required to maintain a fit body. Diets with low levels of salt can weaken the body's sensitivity towards insulin. This reduces the body's ability to metabolize glucose, providing poor levels of energy to the liver, muscles, and nervous system, possibly leading to Type 2 diabetes.

To maintain a healthy blood pressure and smooth functioning of the nerves and muscles, the body needs an adequate amount of salt (sodium). When this optimum level of sodium falls, water enters into the cells to compensate. This results in an imbalance of water to salt ratio in the body, causing swelling in the cells because of excess water.

\section{Sugar and hypertension}

Interaction, risk, and benefits: An emerging but inconclusive body of evidence suggests that increased intake of added sugars might raise blood pressure [11,12]. Studies include animal studies in which rats were fed high doses of fructose, acute ingestion studies in which humans were fed high doses of different sugars, and more recently, epidemiological studies, such as the Framingham Heart Study, in which consumption of $\geq 1$ soft drink per day significantly increased the odds of developing high blood pressure [13]. Nonetheless, results from studies in humans are inconsistent, $[14,15]$ and the chronic effects of a high intake of simple sugars on blood pressure remain uncertain.

How sugar specifically interact with blood pressure (Hypertension): The fact is that an underlying cause of high blood pressure is often related to production of too much insulin and leptin in response to a high-carbohydrate and processed food diet. As insulin and leptin levels rise, it causes blood pressure to increase. Eventually, there may become insulin and/or leptin resistant.

The physiology behind it is that insulin stores magnesium, but if its receptors are blunted and the cells grow resistant to insulin, the body can't store magnesium, so it passes out of the body through urination. Magnesium stored in the cells relaxes muscles.

If magnesium level is too low, the smooth muscle of the blood vessels will be unable to fully relax, and this constriction raises blood pressure. Fructose also elevates uric acid, which drives up blood pressure by inhibiting the nitric oxide in the blood vessels (Uric acid is a byproduct of fructose metabolism; in fact, fructose typically generates uric acid within minutes of ingestion).

Nitric oxide helps blood vessels maintain their elasticity, so nitric oxide suppression leads to increases in blood pressure. So any program adapted to address high blood pressure needs to help normalize both insulin/leptin sensitivity and uric acid level. Eliminating excess sugar/fructose from diet has incidentally been found to address all these three issues (insulin, leptin, and uric acid) in one fell swoop.

\section{Discussion and Conclusion}

High intake of salt raises the amount of sodium in the bloodstream thereby distorting the delicate balance of sodium and potassium in the body which the kidney uses to pull water across cell wall from bloodstream into collecting channel that leads to the bladder. This causes fluid retention which increases the pressure exerted by the blood against blood vessel walls, described as high blood pressure (hypertension).

A large number of studies have been conducted which have consistently shown that salt intake is the major factor increasing population blood pressure. The evidence is greater for the effect of salt on blood pressure than any other dietary and lifestyle factors including a low consumption of fruit and vegetables (i.e. low potassium intake), obesity, excess alcohol intake and lack of physical exercise [16].

Two studies [17,18] both 4 weeks in duration, have compared the effect of different salt intakes on blood pressure $[9,19]$ and $12 \mathrm{~g} /$ day in one, $[19,20]$ and $8 \mathrm{~g} /$ day in the other). Both showed a clear dose-response relationship, i.e. the lower the salt intake achieved, the lower the blood pressure.

Also, high intake of sugar raises insulin and leptin levels in the blood, sometimes leading to insulin and/or leptin resistance. Insulin stores magnesium, but if the cell receptors are blunted and the cells grow resistant to insulin, the body can't store magnesium, so it passes out of the body through urination. Magnesium stored in the cells relaxes muscles. If magnesium level is too low, the smooth muscle of the blood vessels will be unable to fully relax, and this constriction 
raises blood pressure (hypertension). Fructose also elevates uric acid, which drives up blood pressure by inhibiting the nitric oxide in the blood vessels Uric acid is a byproduct of fructose metabolism.

The risks associated with high intake of salt and sugar do not precludes that salts and sugar should be completely avoided in our diets, as they also have their benefits as stated earlier in the article. The watch here should be moderation.

\section{Recommendation}

Intake of the two should therefore be guided by recommended amount as proffered experts.

\section{For salt}

Experts have said that for every 4 gram of salt reduction from average daily intake, there would be approximately $16 \%$ reduction in deaths from strokes, and $12 \%$ reduction in deaths from coronary heart disease, in any population. Reducing salt therefore is one of the quickest ways to reduce blood pressure, particularly if the high blood pressure already exists [21,22].

It is estimated that a reduction of salt by $6 \mathrm{~g} / \mathrm{d}$ would lower blood pressure by $7 / 4 \mathrm{mmHg}$ in individuals with high blood pressure and $4 / 2 \mathrm{mmHg}$ in those with normal blood pressure [21]. The relationships seen in these studies provide evidence that the recommendation to reduce salt intake to 5-6g/day will have a major impact on blood pressure and a further reduction to $3-4 d$ /day will have a much greater effect.

People with or considered at risk of high blood pressure should take extra care to ensure that they keep their salt intake below the recommended maximum of $6 \mathrm{~g}$. This can be achieved by simple changes, such as consuming less processed foods and checking product labels before purchase. Experts recommend no more than 6 grams of dietary salt (i.e. 2.5 grams of sodium) on a daily basis. This makes it approx. 1 teaspoon of salt per day. A good amount of that (about 75\%) is already present in processed meals, breakfast cereals, and breads. Babies less than one year should not consume more than 1 gram of salt, whereas the recommended intake for young children changes as they grow bigger.

\section{For sugar}

As a standard recommendation, total sugar consumption per day should be kept below 37.5g per day for men and below $25 \mathrm{~g}$ per day for women [23]. An insulin resistant patient with high blood pressure, diabetes, heart disease, or other chronic disease, is advised to limit fructose to 15 grams or less per day, until condition has normalized [24,25].

\section{References}

1. Pôrto-Laura CJ, Savergnini-Sílvia SQ, de Castro CH, Mario ÉG, Ferreira Adaliene VM, et al. (2011) Carbohydrate-enriched diet impairs cardiac performance by decreasing the utilization of fatty acid and glucose. Ther Adv Cardiovasc Dis 5(1): 11-22.
2. Marianne UJ, Claus D, Albert MJ, Jakob S, Anne T, et al. (2010) Intake of carbohydrates compared with intake of saturated fatty acids and risk of myocardial infarction: importance of the glycemic index. Am J Clin Nutr 91(6): 1764-1768.

3. Stanley WC, Shah KB, Essop MF (2009) Does Junk Food Lead to Heart Failure? Importance of Dietary Macronutrient Composition in Hypertension. Hypertension 54(6): 1209-1210.

4. Welsha-Jean A, Sharma A, Cunningham SA, Vos MB (2011) Consumption of Added Sugars and Indicators of Cardiovascular Disease Risk among US Adolescents. Circulation 123(3): 249-257.

5. Siri-Tarino PW, Sun Q Hu FB, Krauss RM (2010) Saturated fat, carbohydrate, and cardiovascular disease. Am J Clin Nutr 91(3): 502509.

6. Hu FB (2010) Are refined carbohydrates worse than saturated fat? Am J Clin Nutr 91(6): 1541-1542.

7. MacGregor GA (1999) Nutrition and blood pressure. Nutr Metab Cardiovasc Dis 9(4 Suppl): 6-15.

8. He FJ, MacGregor GA (2001) Fortnightly review: beneficial effects of potassium. BMJ 323(7311): 497-501.

9. Singh RB, Suh IL, Singh VP, Chaithiraphan S, Laothavorn P, et al. (2000) Hypertension and stroked in Asia: prevalence, control and strategies in developing countries for prevention. J Hum Hypertens 14(10-11): 749-763.

10. World Health Organisation (2002) Reducing risks, promoting healthy life. World Health Organisation, Geneva, Switzerland.

11. Feig DI, Soletsky B, Johnson RJ (2008) Effect of allopurinol on blood pressure of adolescents with newly diagnosed essential hypertension: a randomized trial. JAMA 300(8): 924-932.

12. Nguyen S, Choi HK, Lustig RH, Hsu CY (2009) Sugar-sweetened beverages, serum uric acid, and blood pressure in adolescents. J Pediatr 154(6): 807-813.

13. Dhingra R, Sullivan L, Jacques PF, Wang TJ, Fox CS, et al. (2007) Soft drink consumption and risk of developing cardiometabolic risk factors and the metabolic syndrome in middle-aged adults in the community. Circulation 116(5): 480-488.

14. Van der Schaaf MR, Koomans HA, Joles JA (1999) Dietary sucrose does not increase twenty-four-hour ambulatory blood pressure in patients with either essential hypertension or polycystic kidney disease. J Hypertens 17(3): 453-454.

15. Hallfrisch J, Reiser S, Prather ES (1983) Blood lipid distribution of hyperinsulinemic men consuming three levels of fructose. Am J ClinNutr 37(5): 740-748.

16. (1988) Intersalt: an international study of electrolyte excretion and blood pressure. Results for 24 hour urinary sodium and potassium excretion. Intersalt Cooperative Research Group. BMJ 297(6644): 319328.

17. MacGregor GA, Markandu ND, Sagnella GA, Singer DR, Cappuccio FP (1989) Double-blind study of three sodium intakes and long-term effects of sodium restriction in essential hypertension. Lancet 2(8674): 1244-1247.

18. Sacks FM, Svetkey LP, Vollmer WM, Appel LJ, Bray GA, et al. (2001) Effects on blood pressure of reduced dietary sodium and the Dietary Approaches to Stop Hypertension (DASH) diet. DASH-Sodium Collaborative Research Group. N Engl J Med 344(1): 3-10.

19. Blood Pressure Association, BPA, (2008) What Blood Pressure can do to you.

20. (2003) Diet, nutrition and the prevention of chronic diseases. World Health Organ Tech Rep Ser 916: 1-149. 
21. He FJ, MacGregor GA (2002) Effect of modest salt reduction on blood pressure: a meta-analysis of randomised trials. Implications for public health. J Hum Hypertens 16(11): 761-770.

22. He FJ, MacGregor GA (2006) Importance of determining blood pressure in children: Meta-analysis of controlled trials. Hypertension 48(5): 861-869.

23. America Heart Association (AHA) (2011) Heart disease and stroke statistics-2011 update: a report from the American Heart Association. Circulation 123(4): e18-e209.
24. Yu-PothS, Zhao G, Etherton T, Naglak M, Jonnalagadda S, et al. (1999) Effects of the National Cholesterol Education Program's Step I and Step II dietary intervention programs on cardiovascular disease risk factors: a meta-analysis. Am J ClinNutr 69(4): 632-646.

25. Bremer AA, Auinger P, Byrd RS (2009) Relationship between insulin resistance-associated metabolic parameters and anthropometric measurements with sugar-sweetened beverage intake and physical activity levels in US adolescents: findings from the 1999-2004 National Health and Nutrition Examination Survey. Arch Pediatr Adolesce Med 163(4): 328-335

\section{Your next submission with Juniper Publishers} will reach you the below assets

- Quality Editorial service

- Swift Peer Review

- Reprints availability

- E-prints Service

- Manuscript Podcast for convenient understanding

- Global attainment for your research

- Manuscript accessibility in different formats

( Pdf, E-pub, Full Text, Audio)

- Unceasing customer service

Track the below URL for one-step submission https://juniperpublishers.com/online-submission.php 